\title{
Implementasi Logika Fuzzy Untuk Pilot Agent Dalam Simulator Pengendali Lalu Lintas Udara (ATC Simulator)
}

\author{
Elisa Usada ${ }^{1}$ \\ ${ }^{1}$ Sekolah Tinggi Teknik Telekomunikasi Telkom Purwokerto \\ Jalan DI Panjaitan 128, Purwokerto \\ 1'elisa@st3telkom.ac.id
}

\begin{abstract}
Abstrak - Pilot agent memungkinkan objek pesawat di dalam sebuah simulator pengendali lalu lintas udara memiliki tingkah laku (behaviour). Pilot agent dalam simulator ini dirancang untuk dapat merespon gejala cuaca yang diberikan oleh administrator atau instruktur sebelum simulator dijalankan. Respon pilot agent terhadap cuaca buruk kemudian ditampilkan sebagai suatu permasalahan yang harus diatasi oleh pengguna simulator. Gejala cuaca buruk yang akan digunakan dalam penelitian ini adalah wet microburst.
\end{abstract}

Pilot dalam dunia nyata memperkirakan kemungkinan munculnya wet microburst dengan memperhatikan visualisasi cuaca di sekitarnya dan laporan cuaca yang diterima. Parameter gejala wet microburst yang digunakan dibatasi pada parameter intensitas hujan dan perbedaan suhu udara dengan titik embun (dew point spread). Respon pilot agent dibangun menggunakan metode penalaran Fuzzy Reasoning. Hasil reasoning yang dihasilkan dalam penelitian ini selanjutnya dibandingkan dengan hasil reasoning MATLAB untuk mengetahui apakah algoritma yang dihasilkan berjalan dengan baik. Dari hasil perbandingan menunjukkan reasoning yang dihasilkan dalam penelitian ini berjalan dengan baik.

Kata kunci - simulasi pengendali lalu lintas udara, fuzzy reasoning, logika fuzzy, pilot agent.

Abstract - Air Traffic Control Simulator has implemented pilot agent inside. The Air Traffic Control simulator could be used as a media to introduce or to practice in air traffic controlling matter. A scenario to deal with severe weathers is crucial to be presented to the simulator user. The pilot agent in this simulator is designed to have an ability to respond the weather symptom which is given by the administrator or instructor before the simulator run. The pilot agent perform the respond as an issues that must be solved by the simulator user. This research choose a weather symptom called microburst as a trigger for the pilot agent respon.

Pilot in real world predict the probability of microburst by pay an attention to the visualization of the weather around and from the weather report. The pilot behaviour in predicting and dealing with the microburst probabilities is simulated in this research. This research design and apply a reasoning system for the pilot agent in microburst prediction, in air traffic control simulator environment which is developed by the ATC Simulator Team. The weather parameters used in this research are limited to the rainfall intensity and the dew point spread. A fuzzy reasoning method pilot agent in predicting and dealing with the microburst probability is implemented successfully in this research.

Keyword - Air traffic control simulator, fuzzy reasoning, fuzzy logic, pilot agent.

\section{PENDAHULUAN}

Simulator pengendali lalu lintas udara merupakan perangkat lunak yang mensimulasikan kondisi lalu lintas udara, dimulai dari pesawat pada kondisi preflight hingga landing. Kondisi lalu lintas udara yang disimulasikan adalah kondisi lalu lintas pesawat sipil atau komersil. Simulator pengendali lalu lintas udara dapat berfungsi sebagai media pengenalan tentang pengendalian lalu lintas udara kepada pengguna dan dapat menjadi media pelatihan bagi calon pengendali lalu lintas udara.

Sekolah Tinggi Penerbangan Indonesia (STPI) di Curug, Tangerang menggunakan simulator pengendali lalu lintas udara untuk melatih siswa dalam melakukan pengendalian lalu lintas udara. Skenario pelatihan melibatkan siswa, instruktur dan pseudo-pilot. Siswa adalah peserta pelatihan, instruktur bertugas mengatur jalannya pelatihan, dan pseudo-pilot bertugas mengendalikan objek pesawat dalam simulator sesuai dengan panduan yang diberikan siswa. Pelatihan tersebut melatih siswa memberikan panduan kepada pesawat dalam berbagai macam kondisi cuaca.

Simulator pengendali lalu lintas udara yang dibangun oleh Tim ATC Simulator menerapkan pilot agent sebagai pengendali objek pesawat dari dalam sistem. Pilot agent menggantikan fungsi dari pseudo pilot, termasuk menghasilkan suatu permasalahan untuk diselesaikan oleh pengguna simulator 
pengendali lalu lintas udara. Salah satu permasalahan yang dapat dihasilkan adalah perubahan perilaku objek pesawat dikarenakan sesuatu hal yang terjadi di lingkungan. Perubahan perilaku ini dapat mengganggu objek lain dan lalu lintas itu sendiri. Contoh pilot agent di dalam simulator meminta perubahan rute karena adanya kejadian cuaca berbahaya thunderstorm berada di rute yang akan dia lalui. Permintaan perubahan rute ini harus ditanggapi oleh pengguna simulator dengan mempertimbangkan kondisi lalu lintas pada saat itu. Semakin tinggi kepadatan lalu lintas maka tingkat kesulitan mengubah rute juga semakin tinggi karena pengguna simulator harus mempertimbangkan keselamatan pesawat lain dan menjaga jalannya lalu lintas.

Contoh simulator pengendali lalu lintas udara yang menggunakan pilot agent adalah Air Traffic Management Simulation System (ATMSS). ATMSS dikembangkan oleh Adacel Pty. Ltd. ATMSS merupakan simulator pengendali lalu lintas udara yang mengimplementasikan dMARS intelligent agent sebagai pilot agent [1]. dMARS merupakan arsitektur intelligent agent yang dikembangkan oleh Australian Artificial Intelligence Institute.

dMARS memfasilitasi ATMSS sehingga pesawatpesawat yang disimulasikan dalam ATMSS dapat responsif terhadap perubahan lingkungan. Perubahan lingkungan yang terjadi ditanggapi oleh pilot agent dengan melakukan aksi sesuai dengan pengambilan keputusan yang diperlukan [1]. Publikasi menyebutkan bahwa dMARS dibangun menggunakan Procedural Reasoning System (PRS) dengan representasi pengetahuan menggunakan $Z$ specification language sebagai representasi First Order Language (FOL) reasoning [2]. Namun dalam publikasi penelitian tentang dMARS dan ATMSS tidak disebutkan secara rinci bagaimana model tingkah laku pilot yang didapatkan.

Metode reasoning (penalaran) ada beberapa, antara lain propotisional logic, FOL dan fuzzy logic[13]. Telah disebutkan di paragraf sebelumnya bahwa pilot agent yang dikembangkan ATMSS menggunakan FOL. Oleh karena itu dalam penelitian ini penulis akan menggunakan metode reasoning yang lain, yaitu fuzzy reasoning untuk mengembangkan pilot agent dalam simulator pengendali lalu lintas udara.

Kasus yang akan diambil adalah skenario cuaca buruk dalam penerbangan. Lebih spesifik lagi kasus cuaca buruk yang digunakan dalam skenario adalah kasus tinggi rendahnya kemungkinan munculnya microburst. Microburst sangat berbahaya untuk pesawat pada kondisi approach, landing dan take off. Microburst dapat mengakibatkan wind shear dan downdraft sehingga pesawat kehilangan lift (daya angkat pesawat) dan menyebabkan pesawat terhempas jatuh. Microburst sulit dideteksi keberadaannya, seorang pilot menentukan besar kecilnya kemungkinan terjadi microburst berdasarkan gejala-gejala cuaca yang ada. Pilot akan melakukan holding (memutar pada jalur tertentu), mengubah rute atau mendarat di bandara lain jika kemungkinan munculnya microburst tinggi. Penelitian ini mensimulasikan perilaku pilot dalam memprediksi terjadinya microburst dan dalam merespon kemungkinan microburst untuk diterapkan pada pilot agent.

\section{METODOLOG}

\section{A. Simulator Pengendali Lalu Lintas Udara}

Simulator pengendali lalu lintas udara merupakan perangkat lunak yang mensimulasikan kondisi lalu lintas udara, dimulai dari pesawat pada kondisi preflight hingga landing [6]. Simulator pengendali lalu lintas udara diharapkan dapat digunakan sebagai media pengenalan pengendalian lalu lintas udara kepada pengguna dan sebagai alat latihan bagi para calon operator pengendali lalu lintas udara. Tampilan simulator pengendali lalu lintas udara merupakan tiruan Human Machine Interface (HMI) pada sistem pengendali lalu lintas udara di dunia nyata. Pengguna simulator pengendali lalu lintas udara memberi panduan kepada pesawat yang ditampilkan di layar dengan cara mengetikkan kode-kode tertentu menggunakan keyboard.

\section{B. Fuzzy Reasoning}

Teknik reasoning disebut juga teknik penalaran. Teknik reasoning adalah teknik penyelesaian masalah dengan cara merepresentasikan masalah ke dalam basis pengetahuan (knowledge base) menggunakan logic atau bahasa formal yaitu bahasa yang dipahami oleh computer [13]. Fuzzy logic (logika samar) merupakan salah satu logic yang digunakan dalam teknik reasoning.

Teknik fuzzy reasoning meliputi fuzzifikasi, inferensi dan defuzzifikasi . Diagram blok yang lengkap dalam teknik fuzzy reasoning dijelaskan pada Gambar 1[13].

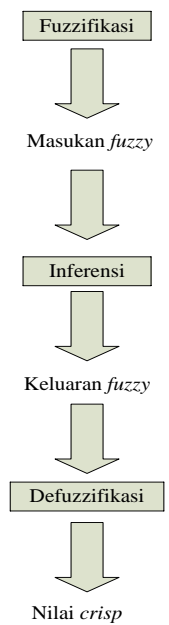

Gambar 1. Diagram blok sistem berbasis aturan fuzzy[8]. 


\section{Fuzzifikasi}

Fuzzifikasi adalah proses mengubah masukan yang memiliki nilai kebenaran pasti (crisp) menjadi bentuk masukan fuzzy. Masukan dalam fuzzy berupa variabel fuzzy. Variabel fuzzy memiliki semesta pembicaraan yaitu keseluruhan nilai yang diperbolehkan untuk dioperasikan dalam suatu variabel fuzzy. Semesta pembicaraan berupa himpunan bilangan real yang senantiasa naik (monoton) dari kiri ke kanan.

Setiap variabel dibagi menjadi beberapa himpunan fuzzy. Contoh variabel fuzzy suhu dibagi menjadi himpunan fuzzy dingin, sejuk, normal, hangat dan panas. Setiap himpunan memiliki domain yang merupakan anggota dari semesta pembicaraan. Domain berupa himpunan monoton naik dari kiri ke kanan.

Fungsi keanggotaan (membership function) adalah kurva yang menunjukkan pemetaan titik-titik input ke dalam nilai keanggotaan. Nilai keanggotaan disebut juga dengan derajat keanggotaan. Fungsi keanggotaan dapat direpresentasikan dengan representasi linear, kurva segitiga, trapesium, kurva bahu, kurva S, kurva bentuk lonceng, kurva BETA dan kurva GAUSS.

\section{Inferensi}

Inferensi adalah melakukan evaluasi setiap aturan fuzzy dengan menggunakan nilai-nilai masukan fuzzy. Metode inferensi ada beberapa, salah satunya adalah metode Mamdani. Inferensi pada metode mamdani dapat menggunakan metoda max. Solusi himpunan fuzzy didapatkan dengan cara mengambil nilai maksimum aturan kemudian digunakan untuk memodifikasi daerah fuzzy dan mengaplikasikan ke output dengan menggunakan operator $O R$ [9]. Metode max dinotasikan sebagai berikut.

$$
\mu_{s f}\left[x_{i}\right]=\max \left(\mu_{s f}\left[x_{i}\right]_{s} \mu_{k f}\left[x_{i}\right]\right)
$$

\section{E. Defuzzifikasi}

Masukan dari proses defuzzifikasi adalah suatu himpunan fuzzy yang diperoleh dari komposisi aturanaturan fuzzy, sedangkan keluaran yang dihasilkan merupakan bilangan pada domain himpunan fuzzy tersebut [8]. Metode centroid atau Center of Gravity (COG) adalah salah satu metode defuzzifikasi yang dapat digunakan pada komposisi aturan mamdani. Metode centroid memperoleh solusi crisp dengan cara mengambil titik pusat $\left(z^{8}\right)$ daerah fuzzy. Metode centroid dirumuskan oleh persamaan 2 .

$$
\begin{aligned}
& z^{8}=\frac{\int_{Z} z \mu(z) d z}{\int_{Z} \mu(z) d z}, \text { untuk variabel kontinu } \\
& z^{8}=\frac{\sum_{j=1}^{\mathrm{n}} z_{j} \mu\left(z_{j}\right)}{\sum_{j=1}^{\mathrm{M}} \mu\left(z_{j}\right)}, \text { untuk variabel diskret }
\end{aligned}
$$

\section{F. Microburst}

Pengaruh microburst terhadap pesawat yang terperangkap di dalamnya dapat dilihat pada Gambar 2 [17]. Pada titik A pesawat akan mengalami pertambahan headwind (kecepatan angin yang melawan arah terbang pesawat) secara tiba-tiba. Pesawat akan mengalami penurunan headwind dan pertambahan tailwind (angin yang searah dengan arah terbang pesawat) secara tiba-tiba pada titik B. Perubahan tersebut mengakibatkan pesawat kehilangan lift (daya angkat keatas) ditambah lagi dengan adanya downdraft (udara yang bergerak ke bawah dengan kuat) dengan kecepatan hingga 60 knots sehingga dapat menyebabkan pesawat kehilangan ketinggian. Microburst umumnya terjadi pada suatu cakupan wilayah kurang dari 1 mil dan di batasan ketinggian antara 1000 feet. Microburst terjadi selama kurang lebih 15 menit dan menghasilkan downdraft hingga 6000 fpm (feet per minute) [12]. Efek ini sangat berbahaya bagi pesawat yang sedang melakukan approach atau take off.

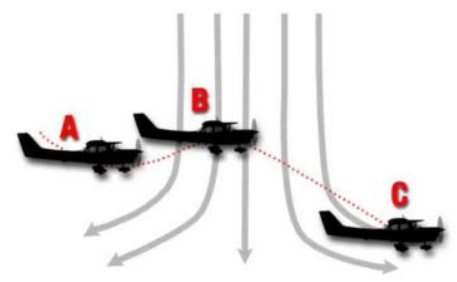

Gambar 2. Pengaruh microburst terhadap pesawat di udara [17].

Penyebab terjadinya wet microburst umumnya karena adanya thunderstorm. Ketika thunderstorm telah terbentuk dan hujan mulai turun, keadaan tersebut merupakan keadaan yang memungkinkan terjadinya microburst. Microburst sering terjadi bersama hujan dengan intensitas tinggi (wet microburst) namun tidak selalu demikian.

Pilot harus memperhatikan perubahan dew point spread pada saat hujan, semakin besar dew point spread maka semakin tinggi pula kemungkinan munculnya microburst [17]. Kemungkinan munculnya microburst pada kondisi dew point spread antara $30{ }^{\circ} \mathrm{F}$ hingga $50{ }^{\circ} \mathrm{F}$ adalah sedang [3].

\section{ANALISIS DAN PERANCANGAN PILOT AGENT YANG RESPONSIF TERHADAP KEMUNGKINAN MUNCULNYA MICROBURST WIND SHEAR DENGAN FUZZY REASONING}

\section{A. Spesifikasi Pilot agent}

Pilot agent dirancang untuk simulasi pengendali lalu lintas udara sehingga pesawat di dalam simulator tersebut dapat memberikan respon terhadap parameter cuaca yang diberikan. Diagram pada Gambar 3 menunjukkan proses penalaran pilot agent. 


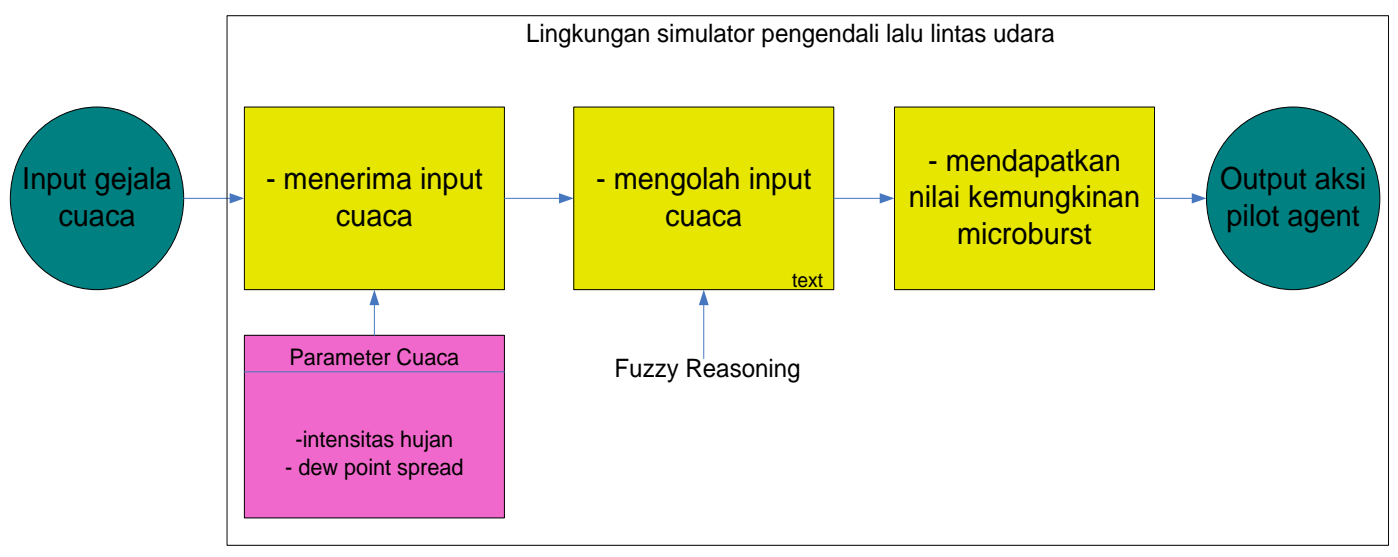

Gambar 3 Diagram pilot agent.

Daftar kemampuan pilot agent yang lebih detail adalah sebagai berikut :

1) Mampu menerima input nilai parameter cuaca Kemampuan menerima input nilai parameter cuaca berupa intensitas hujan $(\mathrm{mm} / \mathrm{h})$ dan dew point spread $\left({ }^{0} \mathrm{C}\right)$ sesuai keinginan penguna.

2) Mampu mengolah input cuaca menjadi nilai kualitatif kemungkinan wet microburst

Mampu mengolah nilai kuantitatif input cuaca yang dimasukkan pengguna menggunakan suatu penalaran untuk menghasilkan nilai kualitatif kemungkinan adanya microburst.

3) Mampu menjalankan aksi sesuai dengan output Mampu menjalankan aksi sesuai dengan keluaran kualitatif kemungkinan munculnya microburst pada wilayah yang dikenai oleh gejala cuaca tersebut. Aksi yang diharapkan dijelaskan pada Tabel 1.

Tabel 1. Aksi pilot agent sesuai nilai kualitatif output

\begin{tabular}{cl}
\hline $\begin{array}{c}\text { Nilai } \\
\text { Kemungkinan } \\
\text { Microburst }\end{array}$ & \multicolumn{1}{c}{ Aksi Pilot agent } \\
\hline Rendah & Meneruskan perjalanan sesuai rute \\
& $\begin{array}{l}\text { Meneruskan perjalanan dengan } \\
\text { menyiapkan aksi untuk mengatasi } \\
\text { microburst dengan menambah } \\
\text { airspeed maksimal 20 knots }\end{array}$ \\
Tinggi & $\begin{array}{l}\text { Mengeluarkan teks permintaan } \\
\text { clearance untuk menghindari wilayah } \\
\text { microburst }\end{array}$ \\
\hline
\end{tabular}

\section{B. Kebutuhan Fungsional Sistem}

Pilot agent harus dapat menjalankan aksi sesuai dengan output kualitatif kemungkinan microburst pada suatu daerah. Sistem akan menyediakan fungsi yang berisi aturan-aturan untuk pesawat yang melintasi daerah yang dikenai gejala cuaca microburst, sehingga pesawat dapat bereaksi sesuai yang diharapkan. Kebutuhan fungsional ini diringkas di Tabel 2.
Tabel 2. Kebutuhan fungsional pilot agent

\begin{tabular}{ll}
\hline \multicolumn{1}{c}{ Fungsi } & \multicolumn{1}{c}{ Deskripsi } \\
\hline $\begin{array}{l}\text { Masukan nilai } \\
\text { kuantitatif } \\
\text { parameter cuaca }\end{array}$ & $\begin{array}{l}\text { Sistem menyediakan blok fungsi } \\
\text { untuk menerima masukan dalam } \\
\text { bentuk file teks. }\end{array}$ \\
$\begin{array}{l}\text { Mengolah nilai } \\
\text { kuantitatif } \\
\text { parameter cuaca } \\
\text { menjadi nilai } \\
\text { kualitatif } \\
\text { kemungkinan } \\
\text { microburst }\end{array}$ & $\begin{array}{l}\text { Sistem menyediakan blok fungsi } \\
\text { perhitungan fuzzy reasoning }\end{array}$ \\
$\begin{array}{l}\text { Menjalankan aksi } \\
\text { sesuai dengan } \\
\text { output kualitatif } \\
\text { kemungkinan } \\
\text { microburst }\end{array}$ & $\begin{array}{l}\text { Sistem menyediakan fungsi yang } \\
\text { berisi rule sehingga ketika } \\
\text { pesawat berada pada wilayah } \\
\text { yang dikenai gejala microburst } \\
\text { maka pesawat dapat melakukan } \\
\text { aksi sesuai keluaran nilai } \\
\text { kemungkinan. }\end{array}$ \\
\hline
\end{tabular}

\section{Perancangan Pilot agent}

Kebutuhan fungsi perhitungan dalam fuzzy reasoning ditentukan berdasarkan tahap-tahap pengolahan metode fuzzy reasoning. Flowchart pada sistem fuzzy reasoning yang akan dibangun dijelaskan di Gambar 4. 


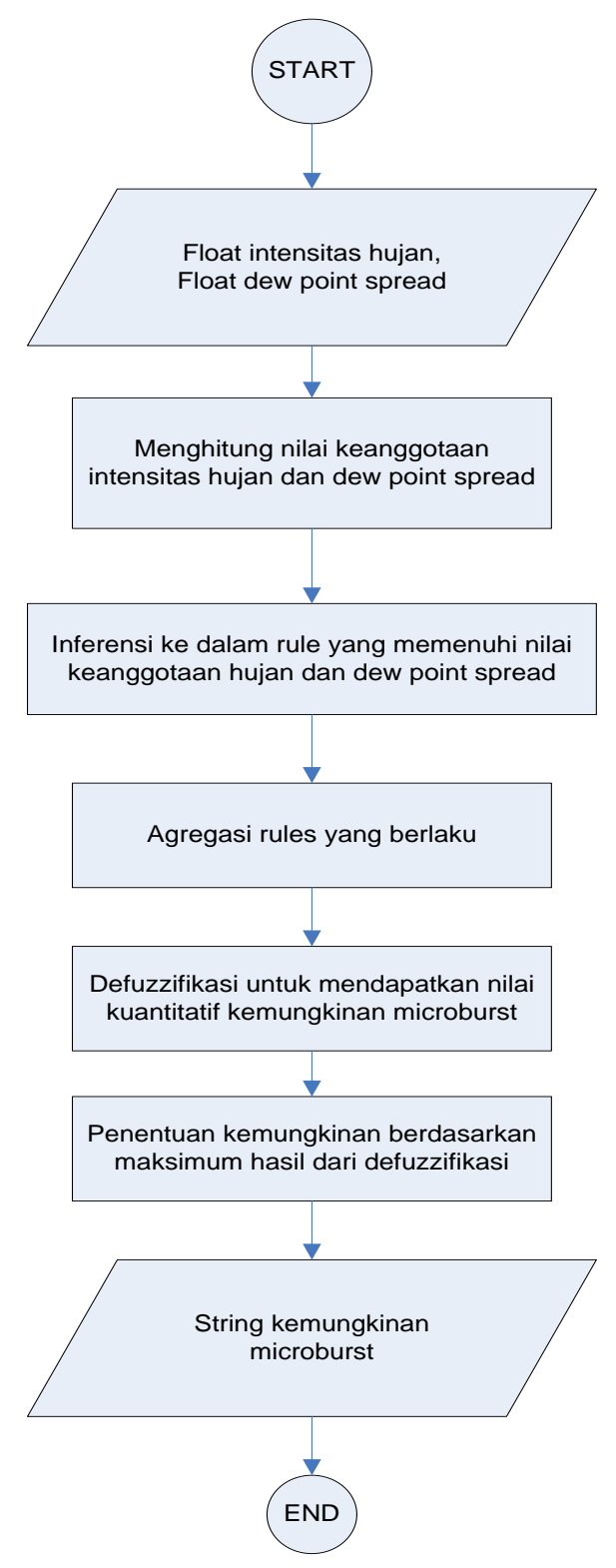

Gambar 4 Flowchart fuzzy reasoning

\section{Fuzzifikasi Gejala Cuaca}

Gejala cuaca yang digunakan dalam penelitian ini dibentuk menjadi variabel dan himpunan fuzzy, dijelaskan pada Tabel 3.

Tabel 3. Tabel variabel dan himpunan fuzzy

\begin{tabular}{ll}
\hline Variabel fuzzy & Himpunan $f u z z y$ \\
\hline Variabel Input: &
\end{tabular}

Variabel Input:

$\begin{array}{ll} & \text { Light } \\ \text { Intensitas hujan } & \text { Moderate } \\ & \text { Heavy } \\ & \text { Very saturate } \\ \text { Dew point spread } & \text { Saturate } \\ & \text { Un saturate }\end{array}$

Variabel Output:

\begin{tabular}{ll}
\hline \multicolumn{1}{c}{ Variabel fuzzy } & Himpunan fuzzy \\
\hline & Low \\
Kemungkinan & Medium \\
terjadinya microburst & High \\
\hline
\end{tabular}

Fungsi keanggotaan untuk variabel tingkat intensitas hujan direpresentasikan pada Gambar 5.

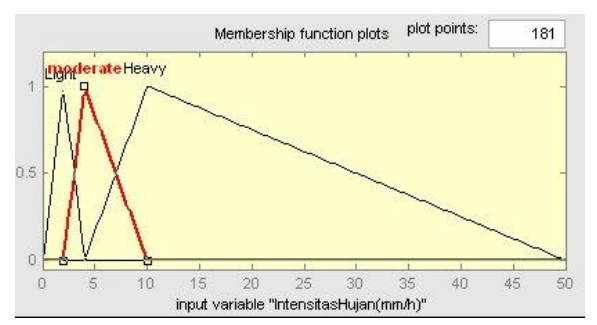

Gambar 5 Fungsi keanggotaan variabel intensitas hujan.

$$
\begin{gathered}
\mu_{\text {light }}(p)=\left\{\begin{array}{lr}
0, & p \leq 0 ; p \geq 4 \\
\frac{p}{2}, & 0 \leq p \leq 2 \\
\frac{4-p}{2}, & 2 \leq p \leq 4
\end{array}\right. \\
\mu_{\text {moderate }}(p)=\left\{\begin{array}{lr}
\frac{0,}{\frac{p-2}{2},} & p \leq 2 ; p \geq 10 \\
\frac{10-p}{6}, & 2 \leq p \leq 4
\end{array}\right. \\
\mu_{\text {heavy }}(p)=\left\{\begin{array}{lr}
\frac{0,}{6-4}, & 4 \leq p \leq 10 \\
\frac{p-p}{40}, & 5 \leq p \leq 10
\end{array}\right.
\end{gathered}
$$

Fungsi keanggotaan untuk variabel besar kecilnya dew-point spread direpresentasikan pada Gambar 6.

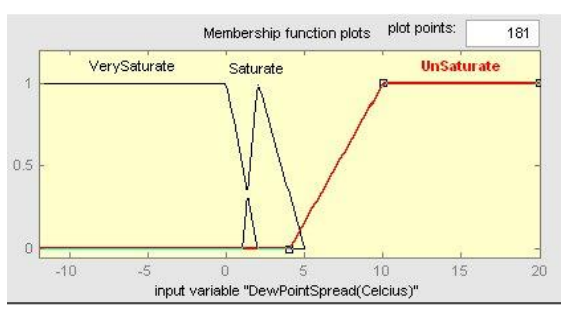

Gambar 6 Fungsi keanggotaan variabel dew-point spread.

$\mu_{\text {very saturate }}(d p s)=\left\{\begin{array}{cr}1, & d p s \leq 0^{\circ} \mathrm{C} \\ \frac{2-d p s}{2}, & 0^{\circ} \mathrm{C} \leq d p s \leq 2^{\circ} \mathrm{C} \\ 0, & d p s \geq 2^{\circ} \mathrm{C}\end{array}\right.$

$\mu_{\text {saturate }}(d p s)=\left\{\begin{array}{lr}0, & d p s \leq 1^{\circ} \mathrm{C} ; d p s \geq 5^{\circ} \mathrm{C} \\ \frac{d p s-1}{1}, & 1^{\circ} \mathrm{C} \leq d p s \leq 2^{\circ} \mathrm{C} \\ \frac{5-d p s}{3}, & 2^{\circ} \mathrm{C} \leq d p s \leq 5^{\circ} \mathrm{C}\end{array}\right.$ 
$\mu_{\text {unsaturate }}(d p s)=\left\{\begin{array}{cc}0, & d p s \leq 4^{\circ} \mathrm{C} \\ \frac{d p s-4}{6}, & 4^{\circ} \mathrm{C} \leq d p s \leq 10^{\circ} \mathrm{C} \\ 1, & d p s \geq 10^{\circ} \mathrm{C}\end{array}\right.$

Fungsi keanggotaan untuk variabel output besar kecilnya kemungkinan terjadinya microburst direpresentasikan pada Gambar 7.

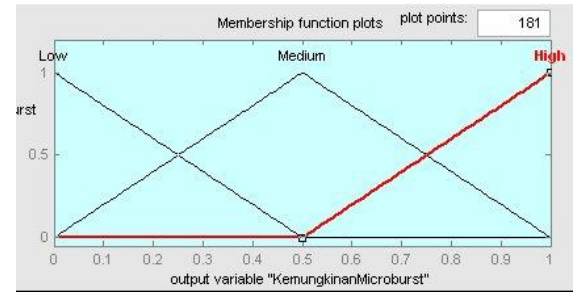

Gambar 7 Fungsi keanggotaan variabel kemungkinan microburst.

$\mu_{\text {low }}(y)=\left\{\begin{array}{cc}\frac{0.5-y}{0.5}, & 0 \leq y \leq 0.5 \\ 0, & y \geq 0.5\end{array}\right.$

$\mu_{\text {medium }}(y)=\left\{\begin{array}{cc}\frac{y}{0.5^{\prime}}, & 0 \leq y \leq 0.5 \\ \frac{1-y}{0.5}, & 0.5 \leq y \leq 1\end{array}\right.$

$\mu_{\text {kigh }}(y)=\left\{\begin{array}{cl}\frac{y-0.5}{0.5}, & 0.5 \leq y \leq 1 \\ 0, & y \leq 0.5\end{array}\right.$

E. Inferensi dan Defuzzifikasi Kemungkinan Munculnya Microburst

Aturan fuzzy untuk kemungkinan munculnya microburst ditentukan seperti pada Tabel 4 dengan tiga nilai linguistik yaitu high, medium dan low. Aturan fuzzy tersebut menjadi basis pengetahuan.

Tabel 4. Tabel aturan fuzzy.

\begin{tabular}{llll}
\hline $\begin{array}{r}\text { Dew point } \\
\text { spread }\end{array}$ & $\begin{array}{c}\text { Very } \\
\text { Saturate }\end{array}$ & Saturate & Unsaturate \\
Intensitas & & & \\
Hujan & Low & Low & Medium \\
Moderate & Low & Medium & High \\
Heavy & Medium & High & High \\
\hline
\end{tabular}

Defuzzifikasi dilakukan dengan menggunakan persamaan 2. Hasil defuzzifikasi kemudian dicari nilai keanggotaannya pada fungsi keanggotaan variable output. Nilai keanggotaan diambil dari nilai keanggotaan maksimal sehingga didapatkan kemungkinan kemunculan wet microburst rendah, sedang atau tinggi.

\section{IMPLEMENTASI DAN PENGUJIAN}

Fuzzy reasoning diterapkan di dalam simulator tersebut dengan membuat blok fungsi untuk menghitung besar kecilnya kemungkinan terjadinya wet microburst, berdasarkan nilai intensitas hujan dan dew point spread. Implementasi dilakukan menggunakan Microsoft Visual C++.

Pengujian yang dilakukan adalah pengujian fungsional. Ada dua prosedur pengujian yang akan digunakan yaitu :

1) pengujian COG yang dihasilkan oleh sistem dengan pengambilan titik sampel yang bervariasi pada saat proses defuzzifikasi,

2) pengujian aksi objek pesawat berdasarkan kemungkinan yang dihasilkan.

Prosedur pengujian pertama selengkapnya dijelaskan pada Tabel 5. Pengujian dilakukan untuk melihat apakah fungsi-fungsi fuzzy reasoning dapat berjalan dengan baik dengan melihat hasil COG. Semakin banyak titik sampel yang digunakan maka seharusnya semakin kecil nilai COG yang dihasilkan. Prosedur pengujian pertama dijelaskan dalam Tabel 5.

Pengujian kedua dilakukan untuk mengetahui apakah objek pesawat dapat melakukan aksi sesuai dengan nilai kualitatif kemungkinan wet microburst yang dikeluarkan oleh sistem. Prosedur pengujian kedua selengkapnya dijelaskan pada Tabel 6.

Hasil pengujian pertama ditampilkan pada Tabel 7 . Hasil pengujian kedua ditampilkan pada Tabel 8.

Tabel 5. Pengujian COG dengan perbedaan jumlah pengambilan titik sampel

\begin{tabular}{|c|c|}
\hline Nama Uji Kasus & Pengujian COG dengan bermacam jumlah titik sampel \\
\hline \multirow{3}{*}{ Prosedur } & 1) Mengubah jumlah titik sampel yang diambil dalam proses defuzzifikasi \\
\hline & $\begin{array}{l}\text { 2) Mencatat perubahan nilai COG dan melihat nilai kemungkinan kualitatif } \\
\text { yang dihasilkan oleh masing-masing COG }\end{array}$ \\
\hline & $\begin{array}{l}\text { 3) Membandingkan hasil pengujian yang terhadap hasil perhitungan } \\
\text { MATLAB }\end{array}$ \\
\hline $\begin{array}{l}\text { Hasil yang } \\
\text { diharapkan }\end{array}$ & $\begin{array}{l}\text { Hasil yang diharapkan adalah semakin banyak jumlah titik sampel yang } \\
\text { diambil, maka COG semakin kecil dan nilai kualitatif kemungkinan yang }\end{array}$ \\
\hline
\end{tabular}




\begin{tabular}{|c|c|}
\hline Nama Uji Kasus & Pengujian COG dengan bermacam jumlah titik sampel \\
\hline \multicolumn{2}{|r|}{ dihasilkan cenderung tetap } \\
\hline \multicolumn{2}{|c|}{ Tabel 6 Pengujian nilai-nilai kemungkinan yang dihasilkan oleh sistem. } \\
\hline Nama Uji Kasus & Kemungkinan wet microburst yang dihasilkan dan aksi pesawat \\
\hline \multirow{3}{*}{ Prosedur } & $\begin{array}{l}\text { 1) memasukkan nilai intensitas hujan dan dew point spread, posisi } \mathrm{x}, \mathrm{y} \text { yang } \\
\text { diberi variabel uji telah ditentukan }\end{array}$ \\
\hline & 2) menjalankan simulator pengendali lalu lintas udara \\
\hline & 3) melihat aksi pesawat dalam simulator untuk setiap nilai kemungkinan \\
\hline $\begin{array}{l}\text { Hasil yang } \\
\text { diharapkan }\end{array}$ & $\begin{array}{l}\text { setelah langkah } 3 \text { dijalankan, diharapkan pesawat akan terus berjalan lurus jika } \\
\text { kemungkinan wet microburst yang dihasilkan oleh sistem adalah low, } \\
\text { menambah airspeed jika kemungkinan wet microburst yang dihasilkan adalah } \\
\text { medium dan mengeluarkan teks perminntaan clearance untuk melakukan } \\
\text { holding untuk nilai kemungkinan high. }\end{array}$ \\
\hline
\end{tabular}

Tabel 7. Tabel hasil pengujian pertama

\begin{tabular}{|c|c|c|c|c|}
\hline No. & Variabel Cuaca & $\begin{array}{l}\text { Jumlah } \\
\text { Titik } \\
\text { Sampel }\end{array}$ & $\begin{array}{c}\text { COG } \\
\text { yang } \\
\text { dihasilkan } \\
\text { sistem }\end{array}$ & Perbandingan dengan MATLAB \\
\hline \multirow{7}{*}{1.} & & 10 & 0.21875 & \multirow{7}{*}{$\begin{array}{l}\text { COG dengan MATLAB }=0.192, \\
\text { COG yang dihasilkan oleh sistem akan } \\
\text { mendekati nilai } 0.192 \text { pada pengambilan } \\
\text { jumlah sampel sebanyak } 100 \text { titik sampel } \\
\text { yaitu COG }=0.197\end{array}$} \\
\hline & & 15 & 0.212987 & \\
\hline & Nilai kemungkinan low: & 20 & 0.207143 & \\
\hline & Intensitas hujan $=2 \mathrm{~mm} / \mathrm{h}$ & 25 & 0.205225 & \\
\hline & Dew point spread $=1^{\circ} \mathrm{C}$ & 30 & 0.202899 & \\
\hline & & 35 & 0.202069 & \\
\hline & & 40 & 0.200862 & \\
\hline \multirow{7}{*}{2.} & & 10 & 0.817391 & \multirow{7}{*}{$\begin{array}{l}\text { COG dengan MATLAB }=0.791 \text {, } \\
\text { COG yang dihasilkan oleh sistem akan } \\
\text { mendekati nilai } 0.791 \text { pada pengambilan } \\
\text { jumlah sampel sebanyak } 83 \text { titik sampel } \\
\text { yaitu COG }=0.791908\end{array}$} \\
\hline & & 15 & 0.8033922 & \\
\hline & Nilai kemungkinan medium: & 20 & 0.802273 & \\
\hline & Intensitas hujan $=4.2 \mathrm{~mm} / \mathrm{h}$ & 25 & 0.798682 & \\
\hline & Dew point spread $=6^{\circ} \mathrm{C}$ & 30 & 0.797436 & \\
\hline & & 35 & 0.795942 & \\
\hline & & 40 & 0.795408 & \\
\hline \multirow{7}{*}{3.} & \multirow{7}{*}{$\begin{array}{l}\text { Nilai kemungkinanhigh: } \\
\text { Intensitas hujan }=6 \mathrm{~mm} / \mathrm{h} \\
\text { Dew point spread }=1.11^{\circ} \mathrm{C}\end{array}$} & 10 & 0.472500 & \multirow{7}{*}{$\begin{array}{l}\text { COG dengan MATLAB }=0.432, \\
\text { COG yang dihasilkan oleh sistem akan } \\
\text { mendekati nilai } 0.432 \text { pada pengambilan } \\
\text { jumlah sampel sebanyak } 150 \text { titik sampel } \\
\text { yaitu COG }=0.436206\end{array}$} \\
\hline & & 15 & 0.458642 & \\
\hline & & 20 & 0.452196 & \\
\hline & & 25 & 0.448870 & \\
\hline & & 30 & 0.446638 & \\
\hline & & 35 & 0.444339 & \\
\hline & & 40 & 0.442997 & \\
\hline
\end{tabular}


Tabel 8. Tabel hasil pengujian kedua

\begin{tabular}{|c|c|c|c|c|c|}
\hline No. & $\begin{array}{c}\text { Intensitas } \\
\text { Hujan } \\
(\mathbf{m m} / \mathbf{h}) \\
\end{array}$ & $\begin{array}{c}\text { Dew Point } \\
\text { Spread }\left({ }^{\circ} \mathrm{C}\right)\end{array}$ & $\begin{array}{c}\text { Nilai } \\
\text { kuantitatif } \\
\text { kemungkinan }\end{array}$ & $\begin{array}{l}\text { Nilai kualitatif } \\
\text { kemungkinan }\end{array}$ & Aksi Pilot \\
\hline 1. & 2 & 1 & 0. 202899 & Low & $\begin{array}{l}\text { Terus berjalan sesuai rute } \\
\text { tanpa melakukan aksi }\end{array}$ \\
\hline 2. & 1 & 2.5 & 0.202899 & Low & $\begin{array}{l}\text { Terus berjalan sesuai rute } \\
\text { tanpa melakukan aksi }\end{array}$ \\
\hline 5. & 6 & 1.11 & 0.446638 & Medium & $\begin{array}{l}\text { Terus berjalan sesuai rute } \\
\text { tetapi dengan menambah } \\
\text { airspeed }\end{array}$ \\
\hline 6. & 3.6 & 4.4 & 0.489804 & Medium & $\begin{array}{l}\text { Terus berjalan sesuai rute } \\
\text { tetapi dengan menambah } \\
\text { airspeed }\end{array}$ \\
\hline 10. & 6.5 & 7 & 0.814394 & High & $\begin{array}{l}\text { Mengeluarkan teks } \\
\text { permintaan clearance untuk } \\
\text { memutar }\end{array}$ \\
\hline 11. & 4.5 & 5.5 & 0.788562 & High & $\begin{array}{l}\text { Mengeluarkan teks } \\
\text { permintaan clearance untuk } \\
\text { memutar }\end{array}$ \\
\hline
\end{tabular}

\section{PENUTUP}

\section{A. Kesimpulan}

Berdasarkan pengujian yang telah dilakukan maka dapat diambil kesimpulan sebagai berikut.

1) Fuzzy logic dapat memfasilitasi pilot agent untuk dapat merespon perubahan lingkungan.

2) Pilot agent mampu menerima masukan parameter cuaca berupa intensitas hujan dan dew point spread untuk kemudian diolah menjadi nilai kualitatif kemungkinan terjadinya wet microburst.

3) Pilot agent mampu menggunakan penalaran berbasis fuzzy dalam pengolahan masukan cuaca menjadi nilai kualitatif kemungkinan terjadinya wet microburst.

4) Pilot agent mampu melakukan aksi sesuai dengan keluaran nilai kualitatif kemungkinan terjadinya wet microburst.

\section{B. Saran}

B. Saran

Cuaca merupakan parameter penting dalam pengambilan keputusan pilot ketika menerbangkan pesawat. Ada berbagai macam cuaca yang berbahaya bagi penerbangan selain microburst. Oleh karena itu sebaiknya dalam penelitian selanjutnya dilakukan halhal sebagai berikut.

1) Penambahan parameter cuaca dapat dilakukan untuk memperbanyak jenis cuaca yang harus direspon oleh pesawat. Contoh penambahan parameter dew point, kecepatan angin dan banyaknya awan sebagai parameter penentu akan adanya kabut atau tidak, yang nantinya berkaitan dengan visibility pilot.
2) Penelitian ini menggunakan asumsi-asumsi cuaca secara umum. Pada penelitian selanjutnmya sebaiknya dilakukan penelitian lebih lanjut tentang pengaruh cuaca yang berbahaya bagi penerbangan.

3) Penelitian ini belum mempertimbangkan seberapa besar kekuatan microburst dan tindakan lanjutan jika terperangkap oleh microburst. Dalam penelitian selanjutnya sebaiknya dilakukan pertimbangan tentang hal tersebut sehingga pilot agent yang dihasilkan dapat lebih detail.

\section{DAFTAR PUSTAKA}

[1] Curmie, Jamie et.al. (1997), Modelling Pilot Behaviour in Air Traffic Control Simulation, http://citeseerx.ist.psu.edu/viewdoc/summary?doi=10. 1.1.55.3060, 5 Maret 2009, 10.00 WIB.

[2] D'Inverno, Mark, Michael Luck, Michael Georgeff, David Kinny, Michael Wooldridge (2004), The dMARS Architecture: A Specification of the Distributed Multi-Agent Reasoning System, http://portal.acm.org/citation.cfm?id=974009.974022, 2April 2009, 14.30 WIB.

[3] Federal Aviation Administration (1988), Advisory Circular: Pilot Wind Shear Guide, U.S Department of Transportation, USA.

[4] Federal Aviation Administration (2007), FAA- $\mathrm{H}-8083$ 25A: Pilot Handbook of Aeronautical Knowledge, US Department of Transportation, Oklahoma City.

[5] Freudenrich, C., How Air Traffic Control Works http://travel.howstuffworks.com/air-traffic-control.htm, Diakses 1 Mei 2008, 17.41 WIB.

[6] Hansman, R. J., Air Traffic Control Overview, http://travel.howstuffworks.com/air-traffic-control.htm, Diakses 1 Mei 2008, 22.32 WIB 
[7] Katz, Amnon (1994), Subsonic Airplane Performance, Society of Automotive Engineers, Inc., USA.

[8] Kusumadewi, Sri, Hari Purnomo (2004), Aplikasi Logika Fuzzy untuk Pendukung Keputusan, Graha Ilmu, Yogyakarta.

[9] Lese, Angela, Thunderstorms and Wind Shear, http://www.crh.noaa.gov/images/lmk/aviationconference/av-conf talks/Wind_shear_final.pdf, 12 Mei 2009, 07.00 WIB.

[10] Proseus, Erik A., A Meteorological Analysis of The American Airlines Flight 1420 Accident, http://www.jrily.com/1420Family/MeteorologicalAnal ysis1420.pdf, 16 Mei 2009, 09.00 WIB.

[11] Sidhom, Mounir (2006), A Teamwork-Oriented Air Traffic Control Simulator, Naval Post Graduate School, France.

[12] Sollman, Henry, Sherwood Harris (1999), Practical Flying Series; Mastering Instrument Flying, McGrawHill, New York.
[13] Suyanto (2007), Artificial Intelligence; Searching, Reasoning, Planning and Learning, Informatika, Bandung.

[14] www.airfleets.net/crash/crash_report_AdamAir_PKKKV.htm, 15 Juni 2009, 14.35 WIB.

[15]

http://www.askcaptainlim.com/index.php?option=com _content \&view=article \&id=876: what-is-amicroburst \&catid $=47$ : windshears $\&$ Itemid $=66,15$ Juni 2009, 14.35 WIB

[16]

http://blog.nationmultimedia.com/ThaiTalk/2007/09/1 8/entry-1, 15 Juni 2009, 14.30 WIB.

[17] $\longrightarrow$ Microbursts and Other Thunderstorm Nastines, http://www.avweb.com/news/safety/182986-1.html, 12 Mei 2009, 08.00 WIB

[18] _ Relative Velocity; Ground Reference, http://www.grc.nasa.gov/WWW/K12/airplane/move.html, 29 Maret 2009, 7:03:49 WIB. 
